\title{
Preparation and characterization of Guar gum Nano Particle through DLS, UV and SEM
}

\author{
Gunti Muthaiah, S.Nagamani, Dr.D.Ramachandran
}

\begin{abstract}
Guar gum Nano particles are smaller in size, due to their smaller size of exact directing, drug release possible, improvement of salutary efficiency and decrease of harmlessness. NPs are low-cost, biocompatible, non-toxic, and biodegradable to chemical alterations. The guar gum Nano particles are widely used in pharmaceuticals. This methods also used for the preparation of Nano particles are nonchemical, precipitation, dialysis, spray drying and mixture of these methods. Current review focus on the synthesis, types, preparation and characterization of Guar gum Nano particles by Ionic gelation method and cross linking method most advanced application related to targeted drug delivery. Nanoparticles act as possible transfers for some classes of cosmetics and drugs. It has been set up that the creation of nanoparticles depends upon the molecular mass of the galactomannan, solvent, surfactant, cross-linker and agitation. The particle size can be determined by scanning electron microscopy studies such as DLS, UV and SEM. The morphology and size of the gum Nano particles are determined by increased technique created spherical nanoparticles of size $10-280 \mathrm{~nm}$. The results are given within the sort of tables and graphs.
\end{abstract}

Index Terms - Guar gum, Tris sodium Trimetaphosphate, sodium hydroxide, ultrapure water, Ionic gelation method.

\section{INTRODUCTION}

Guar Gum Nano particles measures 10-1000nanometres or less. The properties of many conventional materials change when formed from nanoparticles. This is normally as a result of nanoparticles have a bigger extent per weight than larger particles that causes them to be a lot of reactive to another molecules. The size of the particle depends upon nozzle size, atomization pressure, and spray flow, body of water air temperature and quantity of cross linking. ${ }^{1}$ Drug delivery system notion is not novel in the action of some syndromes. Targeting delivery of drugs to carry a necessary dose of drug to the mark, proper carriers of drug were required. These Nano particle carriers have key potential application for the admin of health-giving

Manuscript revised June 4, 2019 and published on July 10, 2019 Mr.G.Muthaih, Department of Chemistry, Acharya Nagrjuna University, Guntur,Andhrapradesh,India.

Mrs.S.Nagamani, Information Technology, Lakireddy balireddy college of Engineering, Mylavarm, Andhrapradesh,India.

Dr.D.Ramachandran, Department of Chemistry,Acharya Nagrjuna University, Guntur,Andhra Pradesh,India. molecule. Lipase is mostly used enzyme in feed, food, pharmaceutics, which can hydrolyze obese into glycerol and full of fatty $\operatorname{acid}^{2,} 3$. Ionic gelation (IG), also called 'ion-induced gelation', ends up in small particles (MPs) nanoparticles (NPs) and with defects like improper surface morphology, fragile particulate system, high dispensability index, and lack of correct surface modification sites to connect purposeful moieties.[4-6]Nanoparticles act as possible carries for numerous courses of drugs such as, antihypertensive ,agents, immunomodulators, hormones and anticancer agents.Macro molecules like proteins, nucleic acids, antibodies and peptides.

[7-8]

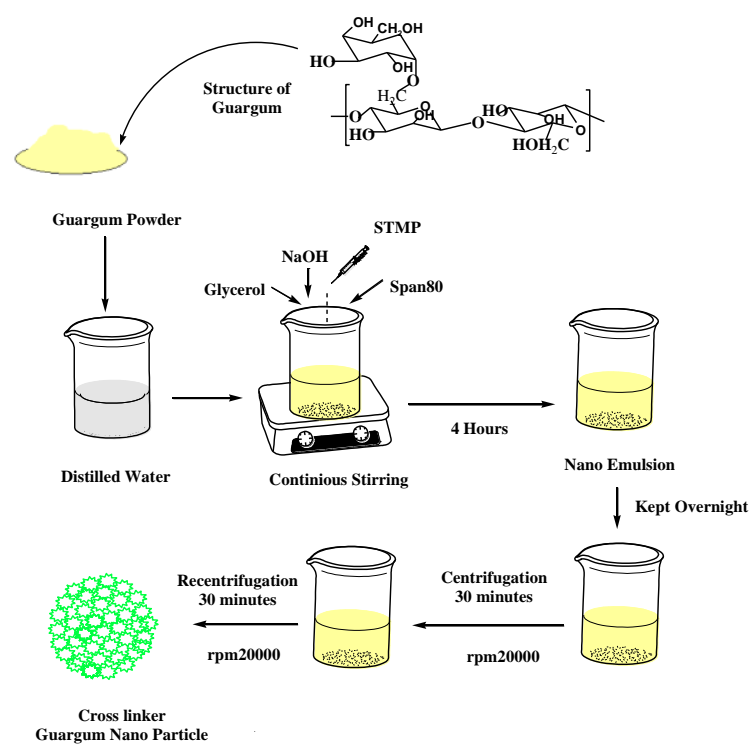

Fig 1:Systematic process of Guar gum Nano Particle preparation based on Ionic Gelation Method

\section{RELATED WORK}

Nano Particles are a category of materials with diameters within the vary from 1 to $100 \mathrm{~nm}$. These systems area unit created unremarkably in nature, and that they area unit referred to as colloids, aerosols and submicron solids; these area unit dirt particles and suspended solids in liquid systems, smoke, clouds and mist. Different nanoparticles area unit deliberately created for distinctive applications in areas of medication and physics[9-11].Fabricated metal colloids are used for the so many years in manufacturing of glass[12-14]. PCA ways applied with numerous qualitative analysis techniques have mature to become themedicine analysis, as well as techniques capable of aiding within the diagnosis of multiple diseases like breast and cervical cancer[17,18] and leukemia [19]. GGNPs has been widly used for breast cancer delivery to the drug unless retarding property and condition 
to microorganism degradation within the intensive. Very little data is out there within the open literature for the chance of exploitation gum based mostly Nano sized materials as a drug carrier In this an attempt is formed in getting ready Nano sized uncoated and catalyst functionalized gum NPs by ionic gelation and cross-linking methodology. Particle size poly dispersity index, and size was established by DLS, UV, and SEM.

\section{III.EXPERIMENTAL}

\section{A .Chemicals required}

Guargum(Mw220kDa),Ttrisodium

trimetaphosphate,Na3P3O9 (STMP), and sodium hydroxide $(\mathrm{NaOH})$.All solutions were ready with ultrapure water.

\section{B. Preparation}

Preparation of cross-linked nanoparticles varied amounts of GG (concentration starting from 0.05 to $0.2 \%$ w/v) were additional in to a $2 \mathrm{M} \mathrm{NaOH}$ solution $(100 \mathrm{ml}$, $\mathrm{pH}=12.0$ ) and were allowed to hydrate for a minimum of $2 \mathrm{~h}$ underneath constant magnetic stirring at temperature.A STMP solution $(100 \mathrm{~mL}$, concentration varied from 0.2 to $10 \% \mathrm{w} / \mathrm{v}$ ) was then additional at a rate of flow of one $\mathrm{mL} / \mathrm{min}$ employing a peristaltic pump, and therefore the reaction mixture was then ceaselessly stirred nightlong. The resultant mixture dispersion was dialyzed against $\mathrm{H} 2 \mathrm{O}$ till neutral $\mathrm{pH}$ (approx.72h). An aliquot of the sample suspension was unbroken for particle size measurements, whereas the remaining product was freeze-dried by freeze drying then keep in an exceedingly desiccator.

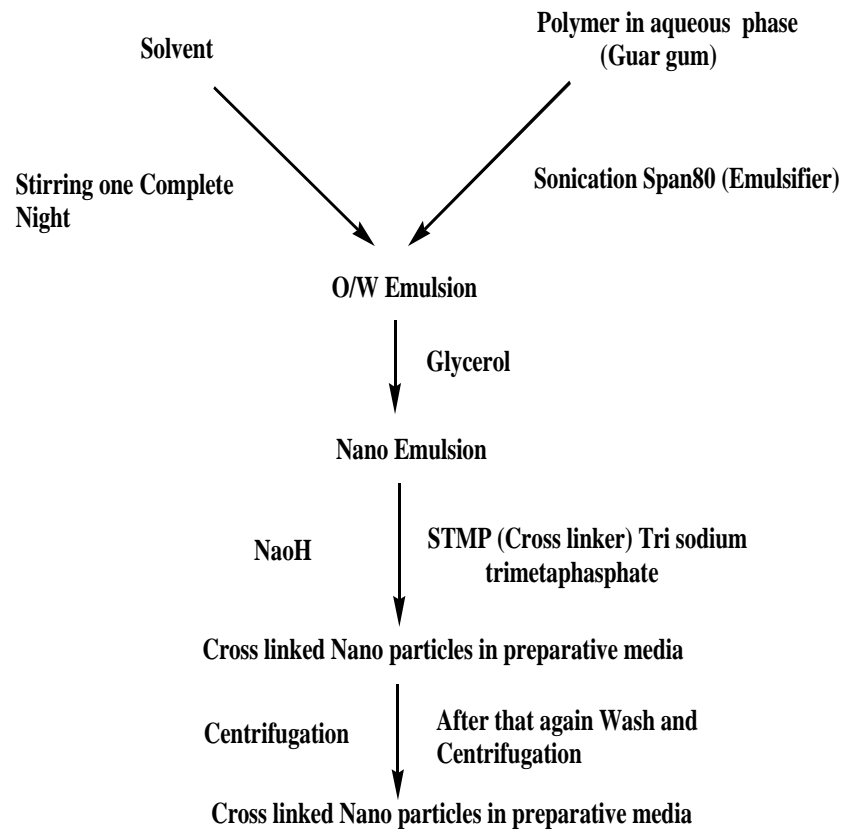

Fig 2: Schematic representation of nano particle preparation

\begin{tabular}{|c|c|c|c|c|}
\hline Batch & $\begin{array}{c}\text { GG } \\
\text { concentrati } \\
\text { on }(\%)\end{array}$ & $\begin{array}{c}\text { STMP } \\
\text { concentrati } \\
\text { on }(\%)\end{array}$ & $\begin{array}{c}\text { Size } \pm \text { SDn } \\
\mathrm{m}\end{array}$ & $\begin{array}{c}\text { PD } \\
\text { I }\end{array}$ \\
\hline GGNP & 0.5 & 10 & $780 \pm 1.4$ & 0.5 \\
\hline
\end{tabular}

\begin{tabular}{|c|c|c|c|c|}
\hline 1 & & & & \\
\hline $\begin{array}{c}\text { GGNP } \\
2\end{array}$ & 0.5 & 5 & $460 \pm 1.3$ & 0.4 \\
\hline $\begin{array}{c}\text { GGNP } \\
3\end{array}$ & 0.5 & 2.5 & $417 \pm 1.2$ & $\begin{array}{c}0.3 \\
2\end{array}$ \\
\hline $\begin{array}{c}\text { GGNP } \\
4\end{array}$ & 0.4 & 1 & $360 \pm 1.6$ & $\begin{array}{c}0.2 \\
8\end{array}$ \\
\hline $\begin{array}{c}\text { GGNP } \\
5\end{array}$ & 0.4 & 0.5 & $537 \pm 8.9$ & $\begin{array}{c}0.2 \\
5\end{array}$ \\
\hline $\begin{array}{c}\text { GGNP } \\
6\end{array}$ & 0.4 & 0.25 & $450 \pm 12.4$ & 0.2 \\
\hline $\begin{array}{c}\text { GGNP } \\
7\end{array}$ & 0.3 & 0.05 & $387 \pm 0.6$ & $\begin{array}{c}0.1 \\
8\end{array}$ \\
\hline $\begin{array}{c}\text { GGNP } \\
8\end{array}$ & 0.3 & 0.03 & $593 \pm 1.3$ & $\begin{array}{c}0.1 \\
2\end{array}$ \\
\hline $\begin{array}{c}\text { GGNP } \\
9\end{array}$ & 0.3 & 0.02 & $208 \pm 0.9$ & 0.1 \\
1
\end{tabular}

Table 1: Characterization of different Nanoparticle

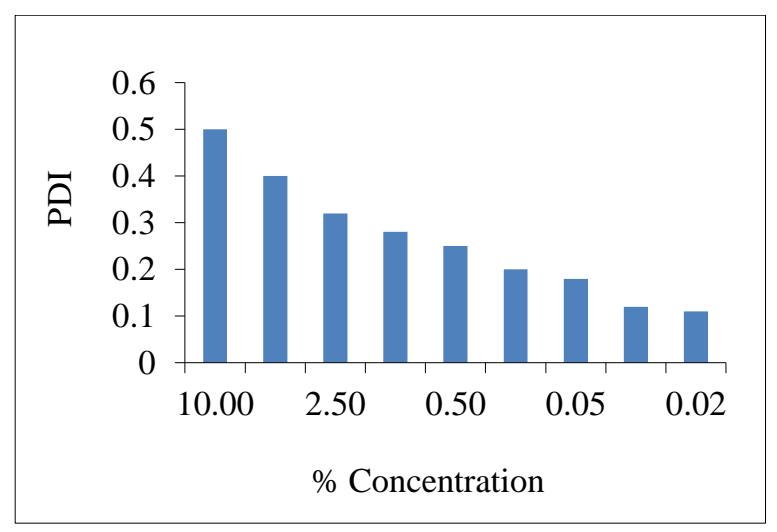

Fig 3: STMP Concentration and PDI

\section{DLS Analysis}

Particle size and DLS measurements the common hydraulics diameter of the nanoparticles determined in water at $25^{\circ} \mathrm{C}$ by dynamic lightweight scattering measurements employing a Malvern Zeta size ZS90 (Malvern Instruments, Worcester, UK). The same Instrument allow the determination of 3 measurements and polydispersity index (PDI). Additionally, period of time dynamic nanoparticle image was achieved by nanoparticle following analysis (NTA) employing a Nano sight LM10 instrument prepared with a sample chamber with a $532 \mathrm{~nm}$ optical maser and a $560 \mathrm{~nm}$ long pass filter. The particle size was calculated exploitation the Stokes-Einstein 


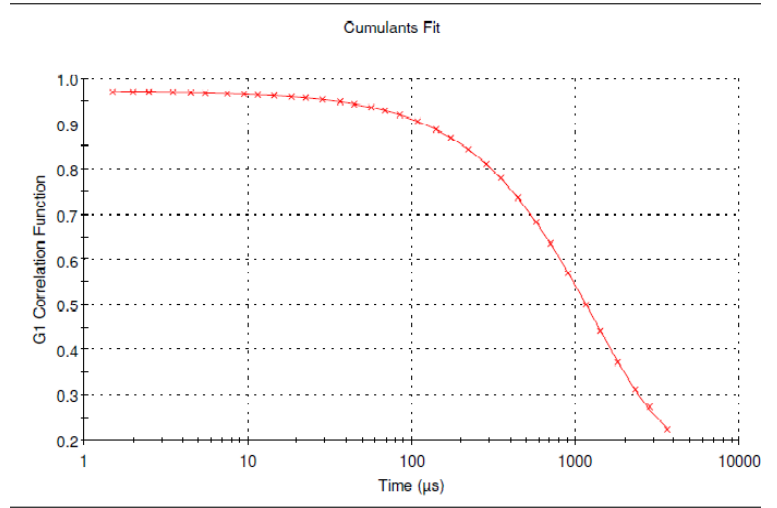

Fig. 4: (b) Guar gum Nano particle Correlation function

\section{UV-Vis Spectra Analysis:}

The reduction of pure guar gum Nano particles was monitored under UV-vis spectrophotometer (Thermo scientific-Genesys10S) $3 \mathrm{ml}$ of sample was withdrawn .The absorbance was measured. UV-vis spectral analysis was done by between 300-700nm.Guar gum nanoparticles formation and the stability of the reduced GGNPs in the filtrate were monitored by using UV-Vis Spectrophotometer (fig. 5a and 5b). An UV-Vis Spectrophotometer is one of the most important to determine the formation of polymer nanoparticles. The results were plotted and Shown in Fig.6a and $6 \mathrm{~b}$. The UV-Vis spectrum Showed an SPR peak of guar gum nanoparticles at $350 \mathrm{~nm}$. It as well known that shape and size of the Guar gum nanoparticles reflects the absorbance peak. The absorption spectrum obtained showed a strong surface Plasmon resonance band maximum at $355 \mathrm{~nm}$ (fig. 5) a characteristic peak of guar gum nanoparticles.

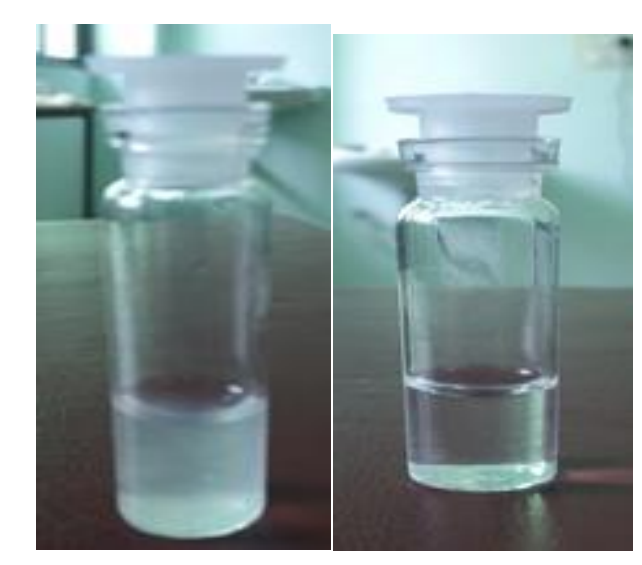

Fig 5: (a) Guar gum with solvent (b) after addition of cross linker STMP

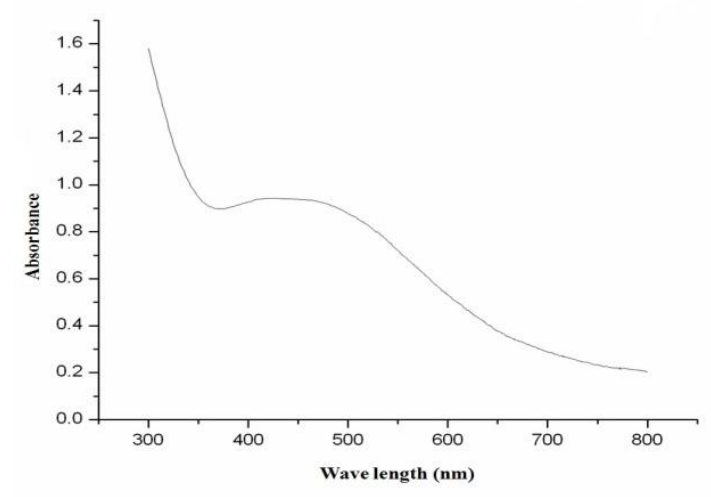

Fig.6 (a): UV-Visible spectral analysis of synthesized guar gum nano particles without cross linker

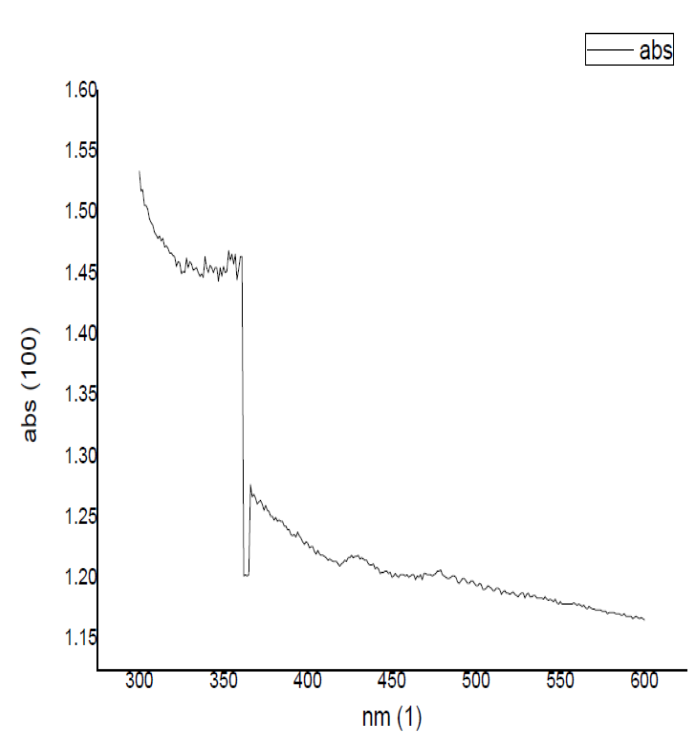

Fig.6 (b): UV-Visible spectral analysis of synthesized guar gum nanoparticles with cross linker (STMP)

\section{E. SEM ANALYSIS}

The scanning microscope (SEM) is one of the foremost versatile instruments on the market for the check and analysis of the microstructure morphology and chemical conformation characterizations.

\section{SURAFCE MORPHOLOGY}

The surface morphology of nanoparticles was studied by scanning microscopy employing a(SEM Jeol JSM-6060LV) Instrument. Sample were placed on stumps, dehydrated with chemical element Associate in Nursing covered with golden alloy in a chemical element atmosphere (current 20 $\mathrm{mA}$, pressure 10e-3 Pa (employing a coater (Quorum, Q 150RES)). 
International Journal of Research in Advent Technology, Vol.7, No.6, June 2019

E-ISSN: 2321-9637

Available online at www.ijrat.org

Fig.7(a) SEM Micrograph of 100nm

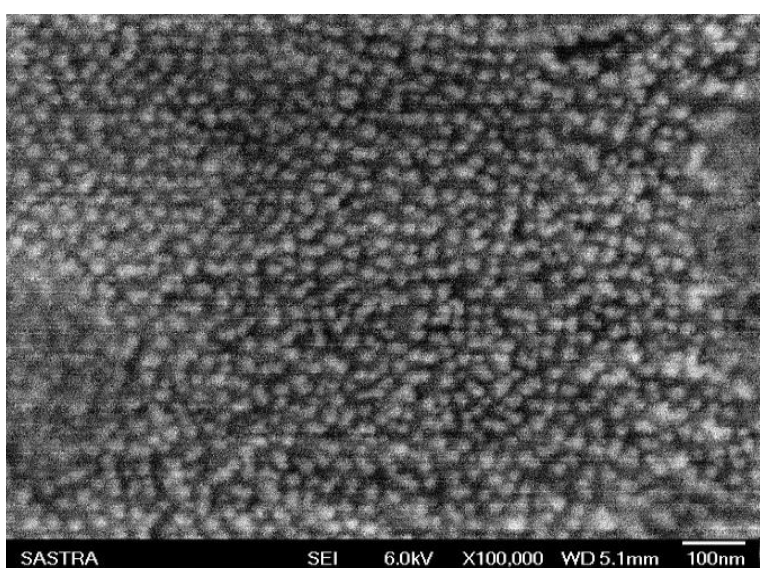

Fig 7(b) SEM micrograph of Guar gum Nano Particles.

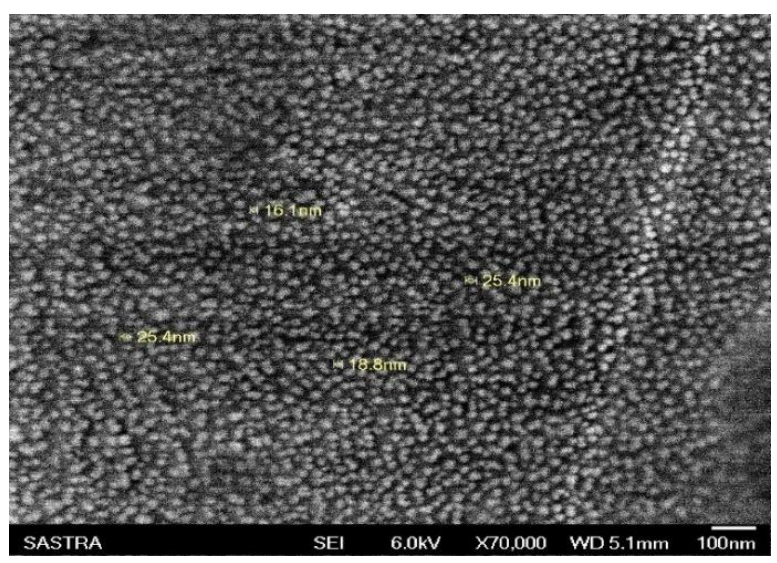

Fig. 7(c) SEM Micrograph of $1 \mu \mathrm{m}$

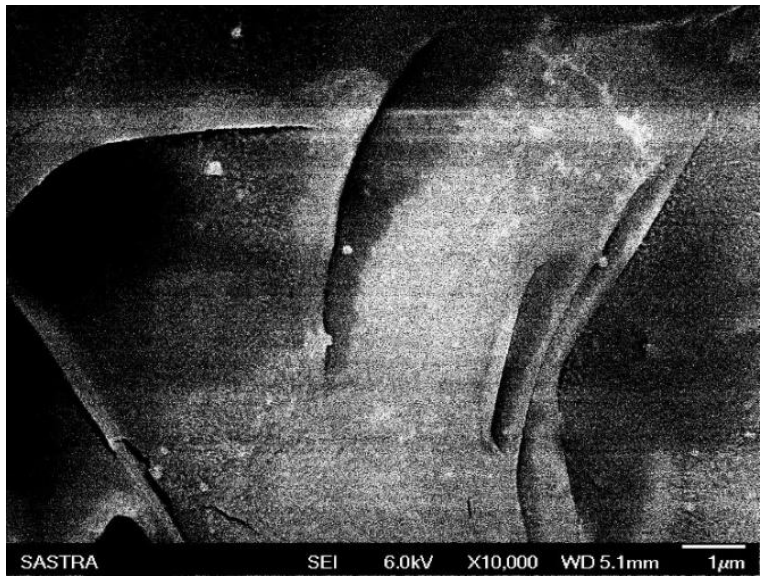

Fig.7(d) Guar gum particles

\section{V.RESULT AND DISCUSSION}

The scanning electron microscope (SEM) is one among the foremost versatile instruments on the market for the investigation and analysis of the microstructure morphology and chemical conformation characterization. Guar gum Nano particles were investigated by SEM as show Fig-7(a,b) The

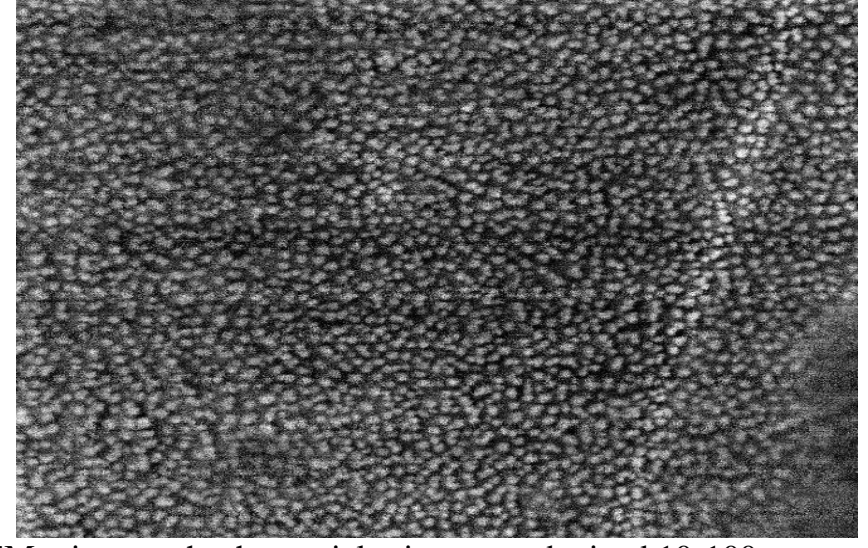

SEM micrographs the particle size were obtained 10-100 nm which is show in the Fig 7(a, b c d).

\section{VI.CONCLUSION}

The techniques namely DLS, UV and SEM mainly used for morphological studies of nanoparticles. Various researchers used these techniques to point out that the made Nano particles were additional or less uniform in size and form. However, challenges and also the success for the researchers during this rising field would rely to an oversized extent on the provision, value and simple handling and performance of the delicate techniques delineate during this paper. Further, the standard and extent of data derived through these techniques i.e. DLS, ultraviolet and SEM chemical analysis, additionally depends to an oversized extent on the extent of understanding of the user, experience and right sample preparation, characterization techniques for nanoparticle employed in drug delivery application.

\section{REFERENCES}

[1] N.V.Ravi Kumar, Nano and Micro particles as controlled drug delivery devices,JPharma Pharmaceut Sci,2000,3(2):234-258.

[2] Sunil A. Recent advances on chitosan -based macro-and nano particles in drug delivery, Journal of controlled Release 100 (2004) 5-28.

[3] Ashutosh Kar, Text book of Pharmaceutical Drug analysis, ISBN (13), P293-311.

[4] Patel VM, PrajapatiBG, PatelMM.Design and characterization of chitosan-containing mucoadhesive buccal patches of propranolol hydrochloride. Acta Pharms 2007 ;57:61-72.

[5] Badawi AA, EI-Laithy HM, EI Qidra RK, EI Mofty H,EI dally M. Chitosan based nanocarriers for indomethacin ocular delivery. Arch Pharm Res 2008;31:1040-

[6] T.Akagi, M.Higashi, T.Kaneko, T.Kida, M.Akashi, Bio macromolecules 7(2006)297-303.

[7] V.P.tarchilin,pharm.RES.24(2007)1-

[8] Sperling R. A., Gil P. R., Zhang F., Zanella M., Parak W. "Biological applications of goldna nopartticles",J., Chem. Soc. Rev. vol.37,pp. 1896-1908,2008.

[9] Weibo C., Ting G., Hao H., Jintao S., "Applications of gold nanoparticles in cancer nanotechnology", Nanotechnology Science Applications, I, pp. 17-32, 2008.

[10] Devika B.Ch.,Arezou A.G., Warren C.W., "Determining the size and shape Dependence of nanoparticle -Uptake into Mammalian Cells",Nano Letters, vol. 6,pp. 662-668,2006.John M.T., Pure\& Appl Chem., 60,pp. 1517-1528,1988.

[11] Klaus, E.; Marion, L.; Martin, M., Matthias, P.;Helmut, S., Method for manufacturing substrates with transparent and color coating stable at 
high temperature and in the presence of ultraviolet rays,U.S. Patent, 6156388,Dec. 5, 2000.

[12] Jan J.G., "On the relationships between SVD, KLT and PCA", pattern recognition, vol. 1-6,pp.375-381,1981.

[13] Salim C., Amrane H., Boualem S., "A new PCA-based method for data compression and enhancement of multi-frequency polarimetric SAR imagery",J. Intelligent data analysis, 6, pp. 187207,2002

[14] Mia H., Sanne E., "Robust PCA and classification in biosciences.

[15] Pichardo J.L., Frausto C., Barbosa o., Huerta, R., Gonzalez J.L., Ramirez C.A., Gutierrez G., Medina C., "Ramanspectroscopy and multivariate analysis of serum sample form breast cancer patients", Lasers Med. Sci.,22,pp. 229-236,2007.

[16] Gonzalez J.L., Rodriguez J., Martinez J.C., Frausto, C., Java L., Aguilar A., Vargas H., Martinez E., presented at Laser Florence 2009, International Congress Laser Medicine with pre conference Courses, November 6-November 7, Springer, Florence 2009,12(26):pp. 91-95.

[17] Martinez J.C., Gonzalez J.L., Frausto C., Miranda M.L., Soria C., Medina J., presented at Laser Florence 2008, International Congress Laser medicine with Pre conference Courses.

\section{AUTHOR PROFILE}
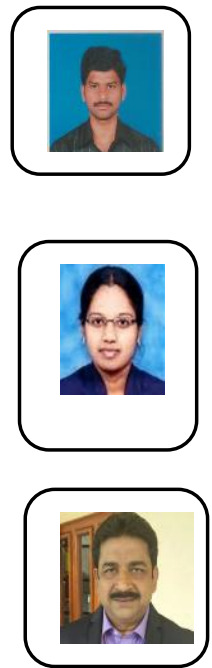

Mr.Gunti Muthaiah Research scholar in department of Chemistry at Acharya Nagarjuna University, Guntur. He published 4 International Journals. He attended 4 national conferences. He has 7 years of teaching experience and 5 years of Research experience.

Sikhinam Nagamani. Working as an Assistant Professor in the department of IT, Lakireddy Balireddy Collge of Engineering,,Mylavarm. She attended five conferences and published 7 Interantional jornals. She has eleven years of Teaching experience.She is a member of ISTE, CSI\& IAENG

Dr.D.Ramachandran working as associate professor in Department of chemistry at Acharya Nagarjuna University,Guntur. He published 38 national journals and 68 International journals. He attended 40 national conferences and 6 International Conferences. 